\title{
Genre and Translation ${ }^{1}$
}

\author{
Christoph Unger \\ Summer Institute of Linguistics, Germany \\ christoph-kuelvi_unger@sil.org
}

\begin{abstract}
This paper discusses a variety of translation problems which are often attributed to genre effects. These effects are analyzed and shown to reveal that genre is a diverse notion which can function in various ways in comprehension processes. To explain these, an account of genre based on relevance theory is proposed. The central claim of this account is that genre information can crucially contribute to the fine-tuning of relevance expectations in complex stimuli. On the theoretical side, this account refines our view of the management of expectations of relevance. On the practical side, it is shown that this account of genre is powerful enough to identify the sources of translation problems attributed to genre effects, and, together with Gutt's $(1991 ; 2000 \mathrm{a})$ explanatory account of translation, guide the translator in a principled way to adequate solutions in given situations.
\end{abstract}

\section{Translation problems related to genre}

Imagine yourself in the position of a tratslator who is assigned to translate example (1) into German:

(1) Seminar motion to establish a working group for research in translation ${ }^{2}$

Whereas, the SIL International Translation Department sponsored a Relevance Theory Update Seminar at Horsleys Green in November 2000, 
And whereas, the participants unanimously expressed a desire for the development of an ongoing Working Group for Cross-Disciplinary Research in Translation,

And whereas, ongoing formal investigation and development of translation theory is an imperative for SIL,

And whereas, the Translation Department has expressed a desire to assume corporate leadership for this venture,

MOVED to request the Academic Services Division of SIL Academic Affairs to endorse the genesis of this group, and to support its development through the Translation Department.

\section{Moved: NN}

\section{Seconded: NN}

Unanimously carried: (all participants present).

One obvious difficulty is to transiate the expression moved to... and the corresponding noun motion. In general, there are two options available: Beschluß, 'resolution', or Antrag, 'formal request'. This text clearly contains a request, so one could be tempted to translate in the following way:

(2) Antrag der Seminarteilnehmer

Aufgrund der Tatsachen, daß das Translation Department on SIL International ein Seminar zum Stand der Forschung in Relevanztheorie unterstützt hat,

daß die Teilnehmer einstimmig ihren Wunsch zur Formierung einer kontinuierlichen Arbeitsgruppe zur Interdiszipinären Forschung über Übersetzung ausgesprochen haben,

daß die ständige formale Forschung und Entwicklung der Übersetzungstheorie eine unumgängliche Aufgabe für SIL ist,

und da fernerhin das Translation Department den Willen bekundet hat, die organisatorische Leitung für diese Unternehmen zu übernehmen,

beantragen wir die Academic Services Division von SIL Academic Affairs die Gründung dieser Gruppe mit Wohlwollen zur Kenntnis zu nehmen und ihre Entwicklung durch das Translation Department zu unterstützen. 
But this translation sounds strange. In a German setting, a mild request such as (1) would not be couched in terms of an Antrag (let alone a Beschluß). It would just be recorded in the minutes, maybe in the following way:

(3) Angesichts des erfolgreichen von dem Translation Department von SIL International durchgeführten Relevance Theory Update Seminars und der besonderen Notwendigkeit für SIL, fortlaufende formale Forschung im Bereich Übersetzungstheorie zu leisten, haben die Teilnehmer einstimmig ihren Willen bekundet, eine ständige Arbeitsgruppe für Interdisziplinäre Übersetzungsforschung zu gründen. Das Translation Department hat den Willen bekundet, die organisatorische Leitung dieser Gruppe zu übernehmen. Die Teilnehmer fordern daher die Academic Services Division of SIL Academic Affairs auf, die Gründung dieser Gruppe mit Wohlwollen zur Kenntnis zu nehmen und diese durch das Translation Department zu unterstützen.

(As a result of the successful Relevance Theory Update Seminar conducted by the Translation Department of SIL International seminar and given the need for SIL for ongoing formal investigation of transiation theory, the participants unanimously expressed their desire to establish an ongoing Working Group for Research in Translation. The Translation Department expressed its desire to provide corporate leadership for this venture. The participants of this seminar therefore request the Academic Services Division of SIL Academic Affairs to endorse the genesis of this group and to support it through the Translation Department).

The problem is that the way the English text (1) is expressed as a whole differs substantially from the way a German text would be expressed in the same situation. In other words: there is a mismatch between genres in English and German with regard to the genres motion, Beschlu $\beta$ and Antrag.

Consider next another translation assignment: translating Homer's Odyssey into contemporary English (Nida, 1964). In Homer's original, the narration is put into poetry. In contemporary English this is a strange combination: narratives normally use largely prose style, whereas extended occurrance of poetic style would not be associated with narration. Again, we have a mismatch of genre.

Yet another task on a translator's desk could be the translation of a Kurdish novel into German. This may contain a dialogue between two participants which ends in the following way:

$(4)^{3}$ A: te şul-ek dî hebû?

You work-IDF other had.2S?

'Did you have anything else to do?'

B: Bes saxi-ya te.

Only health-of yours.

'Only that you may be well'. 
A: Dê başe. Bi xatir-ê te.

PCL good AUX.3S. With pleasure-of yours.

'OK, good. Good-bye'.

B: Bi xêr bi-ç-î.

With grace SJ-go-2S.

'Take care'.

The point is that the question te şulek dî heb $\hat{u}$ 'did you have another thing (for me) to do' is a conventional way of coming to the close of a conversation, and is typically answered in the above way. There is nothing really comparable in German to these turns. In colloquial speech, one may say War sonst noch was? 'was there anything else?'. The answer would be Nein, eigentlich nicht or something like that. Another similar expression is Kann ich noch etwas für Sie/Dich tun? 'can I do anything else for you?', but this is restricted to conversations where practical help was a theme.

Finally consider an example from Bible translation: Isaiah 5:1-7, example (5).

(5) Isaiah 5:1-7 (Working translation of Unger (2001); The Hebrew text with interlinear glosses is presented in the appendix).

(1a) I will sing to my friend/lover a song of my friend to his vineyard. (1b) My friend had a vineyard on a fruitful hilltop (2a) and he digged it up and removed its stones and planted the best species of grapes in it ( $2 \mathrm{~b})$ and he built a tower in its midst, and also a winevat he hewed into it. (2c) And he waited for the vineyard to bring good grapes, but it brought wild (bitter) ones. (3) And now, inhabitants of Jerusalem and people of Judah, judge between me and my vineyard. (4a) What else was there to do for my vineyard which I haven't done, (4b) why did I expect good grapes and it brought forth sour ones? (5a) And now I will let you know what I will do to my vineyard. (5b) I will remove its hedge and it will become firewood. (5c) I will tear down its walls and it will become a trampled land. (6a) I will bring about its peril, it will not be pruned and not be hewn, and in it shall grow thorns and thornbushes. (6b) And I will command the clouds to not let rain fall on it (or: ...the clouds to refrain from letting it rain over it) (7) For the house Israel is the vineyard of the Lord of hosts, and the people of Judah are the planting of his delight, and he waited for justice, but there was only injustice (or bloodshed), for righteousness, but there were only cries.

To understand this text it is crucial to realize that it is formed as a love-song. Hebrew lovesongs employ typical symbols (or allegories): orchard or vineyard typically symbolizes the female partner, the gardener or owner of the vineyard or orchard the male partner, and the vineyard-owner's action of toiling and caring for the vineyard is a symbol for the male partners' expressions of love to his partner. This genre information has important consequences for comprehension. One such consequence is that the assumption that the text is going to be a love-song enables the reader to identify the referent of the first person 
singular referent in (5:1a) as a fictitious female speaker rather than as the prophet Isaiah. Another consequence is that the reader is encouraged to seek the relevance of the text in analogies between what is said about the vineyard and a human love relationship. These analogies will allow the reader to appreciate the emotional impact of the text. ${ }^{4}$

It is easy to see that these aspects would be missed or misinterpreted if the audience wouldn't bring the genre knowledge about love-songs to bear on the interpretation. In particular, it is clear that neither German nor English love-songs use the same symbolisms. It is obvious, then, that a German or English readership will most likely interpret a translation of this text in a different way if the translator does nothing to forestall this. But it is less obvious what the translator should do: while in the first example it was relatively easy to imagine what a German committee would have done in this situation, it is much more difficult to imagine what a German author would do if she or he wanted to get Isaiah's message across.

In all of these examples the translator is faced with more or less difficult problems. The source of these problems lies in the genres involved: a genre may be absent in the culture of the target audience, as the English genre motion is absent in German (which has two different genres for a similar purpose, which may partially overlap, i.e. Beschlu $\beta$ and Antrag). The same genre may exist in two cultures, but may be used for different purposes or may be constituted in different ways. Poetry does exist in contemporary English as well as in Classical Greek, but it is not used in narration in contemporary English culture. Conversation occurs universally, but in Kurdish culture there is a repertoire of conventionalized turns different from that in German culture. Finally, genres may be defined by different 'parameters': love-songs in Ancient Hebrew were constituted by a repertoire of conventionalized symbols which express the theme in a veiled way. But it is not obvious whether love-songs (in Hebrew or any other culture) can be constituted by structural schemas, as is the case with motions, business letters or conversations.

Since there are so many different ways in which genre can function and cause problems for the translator, it seems to be clear that translation theory needs to address this issue. However, on the whole, genre hasn't received a lot of attention in the literature on translation. The most prominent treatment of genre is probably Reiss (1981). She was concerned with the question to what extent different genres may require different standards for equivalence in translation. This doesn't seem to address the problems revealed by the above examples.

Hönig \& Kußmaul (1982) discuss cases of mismatch between genres across cultures. Their claim is that the genre specifies a (socio-cultural) text function, and it is important to translate preserving this function. However, they comment that in cases where some genre or function is unique to one culture, translation is difficult or even impossible (p. 53). With the exception of Homer's Odyssey, all of the introductory examples involve cases where the genre in its make-up and function is unique to the culture of the original author. Consequently, the translator seems to have only one choice: to resignate in the face of these problems. This may be plausible in the case of transiating the motion in example (1). But 
consider the dialogue closing in example (4): it seems to be perfectly feasible to translate it like (6):

(6) A: Gibt es noch etwas, das ich für Dich tun kann?

'Do you have another request what I can do for you?'

B: Nur, daß es Dir gutgehen möge.

'Only that you may be well'.

A: Gut, dann auf Wiedersehen.

'OK, good-bye then'.

B: Auf Wiedersehen.

'Good bye'.

This rendering does sound awkward on the first reading. But it is not incomprehensible, and as more dialogues with closings like this will most likely occur in the novel, it can be expected that the reader will gradually come to appreciate this foreign way of talking. It is a similar experience than that of thousands of readers of Karl May: this author used to directly express foreign ways of expression in German. Initially, these novels may read strange, but after a few pages the reader expects these foreign expressions and has even acquired a sense of what they mean. Apparently we can acquire new conventions fairly easily, and even acquire or generate new genres. Given this, there is little reason for the translator to despair, at least in some of the cases where Hönig \& Kußmaul seem to predict considerable difficulties.

Based on these observations, it seems clear that more needs to be said about genre in translation theory. In this paper I attempt to take steps into this direction. In order to do so I will first consider - in section 2 - the question of what genres are and how they are made up. Next, in section 3, I consider the question of the role genre has in comprehension, arguing that different genres can have a stronger or weaker impact on comprehension in different ways, and that genre does not always have a role in comprehension. The challenge of developing an account of genre which sheds light on these facts is faced in section 4 , where I present a relevance-theoretic account of genre following Unger (2001). In section 5 I will point out some consequences of this account of genres for translation.

\section{Notions of genre}

Looking at the above examples, it is apparent that genre can be characterized in different ways:

-Motions: constituted of a small repertoire of formulas with highly conventionalized meaning. 
-Greek epic (Odyssey): Defined in terms of language style. The overall cast is not different from narrative in general.

-Conversation: may contain conventionalized turns which differ from culture to culture. The overall plan of a conversation is very flexible.

-Love song: characterized indirectly by theme, but more directly by conventionalized symbols. The style is poetic like in other poetic genres. A love-song cannot be determined by an overall (structural) plan.

While genres such as poetry or narrative seem to occur universally in all cultures, others occur only in some, e.g. the English genre motion. Still others may occur widely in cultures, but may be constituted differently in each, e.g. love songs.

Most existing theories of genre, however, concentrate on one aspect of what constitutes genre. Thus, there are theories which distinguish a set of universal genres on the basis of universal features such as narrative, argumentative, hortatory, etc. (Werlich, 1982, Grimes, 1975, Longacre, 1983). Such approaches of genre are in general primarily interested in alleged influences of genre on sentence structure and/or the meaning of morphemes (mostly verb forms) or syntactic constructions. This topic is beyond the scope of this article, but see Unger (2001, chapters 2-4 and 7) for a detailed discussion.

Another influential account of genre is the systemic-functional register and genre theory (Eggins \& Martin, 1997; Downing, 1996; Vázquez Orta, 1996). The central claim of this theory is that aspects of the social context in which texts a produced influence the linguistic realization of the text in systematic ways. These factors were first identified within the register variables mode (e.g., whether the text was produced in a face-to-face interaction, a phone conversation, a lecture, a book), field (subject matter, how much technical knowledge can be assumed, etc)., and tenor (social roles of the communicators). More recently it has been argued in systemic-functional linguistics that an important element of social setting is the staged structure of many communication situations (e.g. service encounters, buying in the marketplace). This aspect of context is what genre is about: a structural schema of the organization of texts for a certain type of communication situation. This schema is taken to be the link between the purpose or function of the genre and the meaning of the individual text (Downing, 1996).

Still other theories use the discourse situation as the main factor constituting the notion of genre, basing a text-typology on such factors as number of speakers, social rank of the speakers, whether the theme of the discourse is fixed beforehand, the character of the theme (whether descriptive, argumentative or associative). Renkema (1993) cites Steger et al. (1974) as a prime example of this approach.

Besides these approaches to genre which focus on one dimension or other, there are prototype-based ones which try to combine several, even disparate, dimensions in characterising genres: Swales (1990) and Paltridge (1995). In Swales' approach, for example, the purpose of a text is the prime determinant of its genre, but other criteria such 
as form, structure and audience expectations are used to determine how close a text is to the prototype of the genre it instantiates.

Yet none of these approaches is satisfactory for the case of Hebrew love-songs. As pointed out above, the love-song genre cannot be established on the basis of a structural schema. Nor does it seem possible to establish a prime purpose for Hebrew love-songs. This means that on Swales' approach, only secondary criteria are available to establish the genre. Of course, the theme of love-songs is fixed beforehand and is of an associative nature. Therefore it seems that along the lines of Steger et al. (1974) a satisfactory characterization of this genre could be found. But the sociological factors alone cannot incorporate the essential point, that the Hebrew love-song genre employs a set of conventional symbols. The universal feature-based approach runs into similar problems: it may be possible to identify some important features of a text such as (5), but the crucial point cannot be established: that the genre information which turns out to be crucial in comprehension is about specific symbols standardly employed in this genre.

The discussion in this section has shown that genre is a diverse phenomenon. There are various ways in which genre can be constituted, and different genres realize different possibilities. Therefore an adequate account of genre needs to shed light on this complexity, more so than the accounts reviewed in this section can do.

It should also be noticed that the literature reviewed in this section does converge on some important insights: genre is an aspect of context, and it is a cultural phenomenon. This indicates that an adequate account of genre needs to be based on a pragmatic theory which assigns context a central place and can shed light on cultural phenomena.

\section{Genre and comprehension}

The above examples (1), (4) and (5) have one thing in common: the recognition of the genre involved gives important clues for comprehension. This observation has given rise to two different claims about the role of genre in comprehension:

(7) genre recognition is essential for comprehension.

(8) genre recognition is helpful for comprehension.

The position expressed in (7) claims that genre has a strong function in comprehension and is mostly associated with researchers in systemic-functional linguistics (Thibault, 1999) and holistic-cognitive linguistics (Paltridge, 1995; Lakoff \& Johnson, 1980). For Thibault, the social process of 'meaning-making' always involves the recognition of genre (1999: 557). Lakoff \& Johnson (1980: 83) claim that the classification of experience is always necessary for comprehension. Their example is that we need to know whether we are engaged in an argument or in a conversation in order to know how to respond. In other words: the recognition of genre is always necessary for comprehension. 
The claim in (8) is that genre has a weak function in comprehension. This claim is advanced mainly by the school which Gerhart (1989) calls the 'traditionalist view', including, among others, Birch (1974) and Fowler (1982). Green (1995) argues in a Gricean framework that the recognition of the type of talk exchange at hand sometimes influences the recognition of scalar implicatures.

Consider again the initial examples. Intuitively, we see that the absence of genre knowledge in a secondary audience can cause a variety of reactions:

-mild irritation (in the case of Kurdish dialogue closure)

-strong irritation and bewilderment (in the case of the English motion)

-a suspicion that one misses something but without a concrete idea of what is wrong (Hebrew love song).

But absence of genre knowledge does not always cause one of these reactions. Consider the case of Homer's Odyssey (i.e. the case of epic poetry). What distinguishes epic poetry from prose is basicaily the overt exploitation of poetic devices. But the reader does not have to recognize poetic devices in order to experience the poetic effects (Sperber \& Wilson, 1995; 1990; Pilkington, 1992; 1994; Gibbs, 1994; 1999). Neither does a hearer or reader have to recognize a narrative plan in order to understand the narration - the recognition of the temporal sequence between events is inferred pragmatically anyway (Wilson \& Sperber, 1998; Unger, 2001: chapter 2). So it is obvious that the absence of genre knowledge cannot impair understanding in these cases. Notice that poetic devices work basically by causing the hearer to invest a high level of processing effort with the guarantee that the effort wiil be rewarded by accessing a wide range of weak implicatures. This sheds light on why people will probably find epic poetry more difficult to read than plain narrative - but this has nothing to do with the accessibility of genre information.

So it appears that genre can sometimes have a role in comprehension, though by no means always. If it has a role in comprehension, then this role may be weak or strong. An adequate account of genre needs to incorporate this flexibility.

\section{Genre and pragmatic theory}

\subsection{Inference, relevance, and comprehension}

At the end of section 3 I noted that most researchers agree that genre is basically an aspect of context. Thus, in order to account for genre one needs to turn to a pragmatic theory which is explicit about the role of context. Relevance theory (Sperber \& Wilson, 1995) fulfills these conditions and I will use this theory as starting point for a pragmatic account of genre.

Relevance theory follows the basic insight of Grice (1957; 1967; both reprinted in Grice, 1989) that communication works basically by inference: the communicator produces 
an ostensive (i.e. overtly intentional) verbal and/or non-verbal stimulus which the addressee needs to process in context as a piece of evidence for inferring the communicator's intention. In the case of verbal communication, the use of linguistic expressions does introduce an element of code. However, this code aspect of verbal communication is still embedded in an inferential phase:

(9) Mike and Sally are about to go on a week-end trip by car, and they are busy packing. Mike says to Sally:

The car is open (Unger, 2001: 26).

In this case, Mike's ostensive stimulus is a verbal expression which provides Sally with evidence for his intention by way of encoding a logical form or propositional schema. Several elements of this schema need to be inferentially enriched in context in order to recognize the proposition which Mike intended to convey (the explicature of her utterance), roughly The doors of the car they own are unlocked. But intuitively, Mike intends to communicate more than just this proposition, and it is easy to see that by accessing appropriate contextual assumptions, Sally can attribute the implicature Sally should start loading it without waiting for Mike to unlock it to Mike.

So far we have seen evidence that communication works by inference, i.e. by processing evidence provided by the ostensive stimulus in an appropriate set of contextual assumptions. It is apparent that this process needs to be constrained somehow, for depending on which context the addressee chooses, he can infer many - even mutually exclusive - conclusions.

Sperber \& Wilson (1995) argue that this constraint is to be found in the way cognition works. The overall goal of cognition is to improve one's representation of the world (Wilson \& Sperber, 2000). However, the mind is always confronted with considerably more information than it can process at any given time. Therefore it must allocate its processing resources efficiently. The most efficient way to do this is to allocate resources to such information which promises the most cognitive effects on the representation of the world (by eliminating false assumptions, providing further evidence for existing ones or by giving rise to further true information in connection with existing assumptions) with little processing effort. Information is efficient in this sense is called relevant in the technical sense. The principle which is expressed informally in these considerations is the cognitive principle of relevance:

(10) The cognitive principle of relevance

Human cognition tends to be geared to the maximisation of relevance (Sperber \& Wilson, 1995: 260).

This principle states nothing but a tendency. The mind's mechanisms and heuristics may not always yield the best results in individual cases, and assessments of relevance do not always produce clear-cut results (see Sperber \& Wilson, 1995: 261-263; 1996 for discussion). Yet 
the tendency expressed in the cognitive principle of relevance is strong enough to make the individual's cognitive process somewhat predictable to others, and this has far-reaching consequences in the case of ostensive communication.

An ostensive stimulus basically calls for interpretation, and this means investment of processing effort on the part of the addressee. But since the mind tends to attend to the most relevant information, it follows that the communicator must have intended her stimulus to be at least relevant enough for the addressee to be worthwhile his attention. Moreover, the more relevant it is for him, the more likely is it that he understands the communicator's intention. Hence, ostensive communication works on the basis of a communicative principle of relevance:

(11) The communicative principle of relevance.

Every act of ostensive communication communicates a presumption of its own optimal relevance (Sperber \& Wilson, 1995: 158).

The presumption of optimal relevance is as follows:

\section{(12) Presumption of optimal relevance}

a. The ostensive stimulus is relevant enough for it to be worth the addressee's effort to process it.

b. The ostensive stimulus is the most relevant one compatible with the communicator's abilities and preferences (Sperber \& Wilson, 1995: 270).

This presumption of relevance provides a working hypothesis for interpretation. It amounts to a claim that by investing little processing effort, the addressee can find an interpretation which achieves enough cognitive effects so that it satisfies his expectations of relevance. This in turn motivates the following comprehension procedure:

\section{(13) The relevance-theoretic comprehension procedure}

Follow a path of least effort in computing cognitive effects:

(a) Consider interpretations (reference assignments, contextual assumptions, implications, etc). in order of accessibility.

(b) Stop when your expectations of relevance are satisfied (Unger, 2001, 26).

\subsection{Expectations of relevance and genre}

In order to relate the relevance-theoretic comprehension procedure more specifically to genre, we need to further examine the role of the presumption of optimal relevance and the expectations of relevance raised in a particular case. The presumption of relevance is a member of the set of assumptions which are communicated by the stimulus; it is one that unlike others - is communicated by principle. As with all communicated assumptions, the addressee doesn't have to accept it at face value. It is, as I put it above, a working 
hypothesis. In case the addressee trusts the communicator enough, he will accept it at face value and expect that the stimulus will be optimally relevant to him. However, the addressee may be more cautious and expects just that the speaker may have attempted or (in deceptive cases) purported to be relevant (Sperber, 1994). In other cases, the addressee's expectations of relevance may be more specific with respect to the kind or level of cognitive effects. Consider the case of indirect answers:

A: Did you have a good meeting?

B: We discussed procedural matters for most of the time.

According to Sperber \& Wilson (1995), questions resemble relevant answers and thereby indicate what type of propositions would be regarded as relevant by the one who posed the question. In (14), A's question makes it manifest to B that A regards propositions of the form $B$ had a good meeting or $B$ did not have a good meeting as relevant. It is then obvious for B that A will expect his answer not just to be optimally relevant, but optimally relevant. in the sense of giving access to a proposition of one of the indicated types. This expectation in turn explains how B's answer conveys the implicature $B$ did not have a good meeting. The following table shows how this interpretation processed may be analyzed. In the lefthand column, paraphrases of mental representations entertained by $A$ are listed, and the right-hand column indicates their source and status.

\begin{tabular}{|c|c|}
\hline $\begin{array}{l}\text { (a) B has said "We discussed procedural } \\
\text { matters for most of the time". }\end{array}$ & Decoding of B's utterance \\
\hline $\begin{array}{l}\text { (b) Information about whether B had a good } \\
\text { meeting would be relevant to A. }\end{array}$ & $\begin{array}{l}\text { Assumption made mutually manifest by } A \text { 's } \\
\text { utterance. }\end{array}$ \\
\hline $\begin{array}{l}\text { (c) B's utterance will be optimally relevant to } \\
\text { A. }\end{array}$ & $\begin{array}{l}\text { Presumption of optimal relevance, communicated } \\
\text { on the basis of the communicative principle of } \\
\text { relevance. }\end{array}$ \\
\hline $\begin{array}{l}\text { (d) B's utterance will be optimally relevant to } \\
\text { A by providing information as to whether B } \\
\text { had a good meeting. }\end{array}$ & $\begin{array}{l}\text { Expectation of relevance created by A's adopting } \\
\text { the presumption of optimal relevance and } \\
\text { enriching it in the light of the mutual cognitive } \\
\text { environment. }\end{array}$ \\
\hline $\begin{array}{l}\text { (e) B and his colleagues discussed } \\
\text { procedural matters for a substantial amount } \\
\text { of time at the meeting in question. }\end{array}$ & $\begin{array}{l}\text { Development of the logical form of } B \text { 's utterance. } \\
\text { Accepted as the explicature of this utterance. }\end{array}$ \\
\hline $\begin{array}{l}\text { (f) Discussing procedural matters for a } \\
\text { substantial amount of time is an unpleasant } \\
\text { experience in meetings. }\end{array}$ & $\begin{array}{l}\text { Encyclopaedic information. Accepted as an } \\
\text { implicated premise. }\end{array}$ \\
\hline $\begin{array}{l}\text { (g) If one had an unpleasant experience at a } \\
\text { meeting, one did not have a good meeting. }\end{array}$ & $\begin{array}{l}\text { Encyclopaedic information. Accepted as an } \\
\text { implicated premise. }\end{array}$ \\
\hline (h) B did not have a good meeting. & $\begin{array}{l}\text { Conclusion from }(f) \text { and }(g) \text { which satisfies the } \\
\text { expectation of relevance }(d) \text { raised by } B \text { 's } \\
\text { utterance. Accepted as an implicated conclusion. }\end{array}$ \\
\hline
\end{tabular}


This discussion highlights the point that the first step in comprehension is that the addressee adopts an expectation of relevance on the basis of the presumption of optima! relevance and maybe from very easily available contextual assumptions. These expectations of relevance will then further determine the specific strategies which the comprehension procedure follows. In case the expectations of relevance are less specific with regard to kinds of effects but concern more the level of effect to be expected, the comprehension strategy will be mostly effort-based. In case the expectations of relevance are specific in terms of kind of effects, the comprehension strategy will be mostly effect-based in the sense that only interpretations which lead to effects of the type expected will be accessed in order of accessibility (Sperber \& Wilson, 1995: 266-272; Unger, 2001:146).

So far we have considered only simple stimuli, i.e. ones that consist only of one utterance or a gesture. But ostensive stimuli can be more complex than that. Consider the case of a librarian explaining a group of students how to use the library's electronic catalogue. The complexity of this stimulus is not just in the fact that it consists of several verbal utterances, pointing gestures and demonstrating actions, but also in the fact that it obviously will extend over a considerable period of time and involve many utterances and gestures. Texts, too, are a case of complex stimuli in this sense.

Complex stimuli raise the presumption of their optimal relevance once for the whole stimulus. The individual parts of this complex stimulus are then expected to contribute to its overall relevance in a cumulative way. Thus, initial utterances, for example, may be worth the hearer's attention even though they don't raise a lot of expectations of relevance on their own; but they can be expected to affect the interpretation of other utterances, i.e. they fine-tune the addressee's expectations of relevance during processing (Blass, 1990: 77; Unger, 2001: 138-139).

The central claim of Unger (2001) is that genre information is contextual information which is easily accessible for the fine-tuning of expectations of relevance in complex stimuli. In other words, it provides the audience with clues as to how the text might unfold or how the text will achieve relevance. In order to fulfill this role, it must be highly accessible in the early stages of the comprehension procedure. Therefore, claiming that genre information is information which is used for fine-tuning expectations of relevance in complex stimuli seems to amount to the stipulation that genre information is always easily accessible, in contrast to other kinds of contextual information which vary in accessibility from situation to situation, subject to their organization in memory. ${ }^{5}$ How can this curious property of genre information be explained?

An answer to this question comes from Sperber's (1996) account of cuiture in terms of an epidemiology of representations. Sperber claims that cultural knowledge is shared by a population because it is information that has often been found important in establishing the relevance of phenomena or communicative behaviour. The more often a certain assumption is used, the more accessible it is in memory.

If there is a consensus in the literature on genre, it is that genre information is cultural (Eggins \& Martin, 1997 and references therein; Kitis, 1999; Swales, 1990; Paltridge, 1995). On Sperber's (1996) relevance-based account, cultural information is easily 
accessible because it is constantly communicated and used in cognitive and social tasks. It follows that genre information should be easily accessible for cognitive tasks by virtue of its success in spreading over a population. What looked like a stipulation is shown to have a deeper explanation in the consequences relevance theory has for explaining culture.

Finally, let us consider in more detail the ways in which genre information may finetune expectations of relevance of complex stimuli. Recall that expectations can be rather general in that they relate just to the level of cognitive effects, or they can be more specific, relating to the type of effects to be expected. In the case of complex stimuli, expectations of relevance can also provide specific expectations as to how the text will unfold. This is especially the case in the familiar cases of highly conventionalized genres, e.g. motions (example (1) above), German letters of recommendation of an employer for an employee, business letters, or legal contracts (Klinge, 1998). In these cases, genre information gives clues to the addressee which utterances to find at which stage in the text. Expectations of this sort are highly specific. Relevance expectations concerning the way the text will unfold can also be somewhat less specific by relating to the sort of content that specific parts of the text will have. In a linguistic article, for example, the expectations will be that one finds an abstract, an introduction, the main argument, a conclusion and a bibliography. Other examples of genres where the expectations about the unfolding of the text may be more or less precise in this sense include sonnets, short stories, weather forecasts, news bulletins, and advertisements (Unger, 2001, 295). Yet another way in which expectations of relevance may be specific is about the type of cognitive effects that the text will have. The Hebrew love song genre is a case in point: genre information gives the addressee clues as to which cognitive effects certain symbolic expressions will have, i.e. how to interpret them. The expectations are not about form but about content. ${ }^{6}$

On this relevance-theoretic account, genre is a cultural concept which gives access to information which helps the addressee to fine-tune expectations of relevance. This information is accessed in the normal course of the cost-sensitive comprehension procedure in a process which adjusts context, content and implicit import in a parallel inferential procedure (Sperber \& Wilson, 1998; Wilson \& Sperber, 2000). In contrast to this, most other theories of genre assign the recognition of genre a special place: Kitis (1999) and Holdcroft (1979) claim that the genre regulates which conversational maxims become operative. Genre recognition would therefore be a process which precedes the maximbased pragmatic comprehension procedure. Green (1995) suggests that text-type recognition is an important factor in determining what the current talk-exchange requires, thereby determining the content of the Gricean maxims in a given instance. Lakoff \& Johnson's (1980) claim that we need to categorize our experience in order to comprehend also seems to suggest that a first step in the comprehension procedure should be to determine the closeness of the text to a genre concept. But there is some evidence which poses problems to such accounts: a text such as (5) can at first adhere to a genre and then take unexpected turns and yet not be judged deviant. Likewise, texts may vary considerably from the standard form specified in the genre concept and not be seen as deviant. ${ }^{7}$ These difficulties do not arise in the proposed relevance-theoretic account where genre 
information is seen as contributing to the relevance-oriented comprehension procedure and come into play only when needed. On this account, the cognitive role of genre is to provide access to information which may focus the inferential processes on a certain direction by making expectations of relevance more specific. So even if some genre concepts may contain schemas of the form discussed e.g. in Eggins \& Martin (1997), this relevancetheoretic account assigns them a different place in pragmatics.

\section{Some consequences of the relevance-theoretic account of genre for translation}

Having outlined a relevance-theoretic account of genre I will now turn to the question how this account could help with solving the translation problems discussed in section one. In doing so I will combine this account of genre with Gutt's $(1991 ; 2000 \mathrm{a})$ relevance-theoretic account of transiation.

\subsection{On the nature of translation problems caused by genre}

On an inferential account of communication, the communicator chooses the formal properties of her stimulus by the criterion of how effective they will be in achieving the intended effect in the audience, and not for the sake of the properties themselves. The speaker who says The strawberries have been eaten chose the passive not for the sake of the passive form, but for the sake of conveying that she makes a statement of the fact without inviting the understanding that she implicitly casts blame on someone, as the active alternative Someone has eaten the strawberries may. Thus, formal properties of linguistic stimuli can be seen in a language-independent way as communicative clues (Gutt, 1991; $2000 \mathrm{a}, \mathrm{b}$ ), and utterances of different languages can be compared as to whether they share communicative clues. If two utterances share all their communicative clues, they lead to the same interpretation - provided they are processed in the same context.

We have seen that at least in some cases such as in (5), accessing the intended genre information can be crucial for the audience to arrive at the intended interpretation. The question arises whether genre has this function because it constitutes a communicative clue. At first sight it appears that this should be the case. But on the relevance-theoretic account, genre is not a formal property of texts, and can therefore not be seen as a communicative clue. Rather, genre information is part of the mutual cognitive environment between communicator and audience. More specifically, it is part of this mutual cognitive environment in virtue of its epidemiological distribution in the society of which the original author and the primary audience is part of, and it has the effect that the communicator can choose the communicative clues of her stimulus relying on the audience's capability to use this information in interpreting her text.

However, the translator communicates in a secondary communication situation: she is communicating the original communicator's intention to an audience which is not part of the original audience's society and is possibly lacking cultural assumptions which the 
primary audience shared with the author. There is typically a contextual gap between primary and secondary audience, the bigger the greater the cultural distance between the audiences (Gutt, 1991: 72-75; 2000a: 76-79). Problems in translation caused by genre are related to a contextual gap between the cultures involved.

Thus, the relevance-theoretic account of genre presented in section 4 helps to identify the source of the translation problems which genre may give rise to: they are caused by a contextual gap between primary and secondary audience, not by formal properties of the text itself. This immediately raises the question how problems caused by such a contextual gap between the audiences may be overcome.

\subsection{The nature of translation and strategies for solving genre-based translation problems}

As a first step in coming to a principled solution to such problems, it is important to consider the nature of translation. Gutt $(1991 ; 2000 \mathrm{a})$ argues that translation is a special mode of interlingual communication: by producing a translation the translator makes manifest to the target audience the fact that the translator intends her stimulus (the translation) to be relevant in virtue of the resemblance it bears in meaning to the original text (i.e. in virtue of its sharing explicatures and implicatures with the original text). This mode of communication engages the basic cognitive capacity of humans to communicate by exploiting resemblance relations between representations, i.e. by exploiting metarepresentational relations (Sperber \& Wilson, 1995; Wilson \& Sperber, 1988; Gutt, 1991; 2000a; Sperber, 2000; Wilson, 2000). In this respect translation parallels speech quotation: translation is a case of interlingual quotation. As in quotation, the intended resemblance to the original in translation may be closer or looser as determined in the particular case by considerations of relevance.

Therefore, an important question the translator has to ask herself is what degree of resemblance she should aim for. If this degree of resemblance is relatively low, then it may not matter whether due to the contextual gap the secondary audience will not get certain aspects of the original, e.g. some weaker implicatures. Or the translator may be able to convey some implicatures explicitly. A third option may be to insert words or phrases in the translation which provide the target audience access to some crucial contextual assumptions. However, all these options cause the translated text to depart from the meaning of the original.

A translation of (5) along these lines might look like (16) or (17):

(16) (1a) I will sing to my lover a song of my friend to his beloved - a delightful vineyard. (1b) My friend bad a vineyard on a fruitful hilltop...

(17) (1a) I will sing to my lover a song of my friend to his beloved - she who is like a delightful vineyard. (1b) My friend had a vineyard on a fruitful hilltop... 
In these versions, a parenthesis is added to the first sentence giving the hearer a clue that the female partner in the love-relationship is talked about as a 'vineyard'. This results in a replacement of the symbolic expression kerem 'vinyard' in the original with its resolution '(the) beloved' in the translation. Thus, a certain distortion is inserted in the text with the result that the audience has access to contextual assumptions which it would otherwise not have, and which are cnucial for understanding the intended meaning of the following text. However, if the degree of resemblance aimed for is higher, then such an approach is not applicable. The closer the interpretive resemblance aimed for, the more it is relevant that this resemblance includes not only the sum total of cognitive effects the original aimed for, but also the way in which they are achieved. For on the inferential account of communication, there is a difference whether a certain aspect of what the communicator intended to convey is expressed explicitly in the text (by way of communicative clues) or whether it is conveyed as an implicated aspect of the meaning conveyed (an implicit part of the explicature of an utterance, or an implicature). In the latter case, the communicator makes it mutually manifest to herself and the audience that she believes the audience to share some knowledge - the contextual information that is needed to infer the intended implicated conclusion. One function of communication - apart from conveying information - is the management of the mutual cognitive environment, which influences the social relation between communicator and audience as well as further possibilities of communication (Sperber \& Wilson, 1995: 61-62). Consider for example a variant of example (9): in the same situation, Mike says to Sally (18):

(18) Sally, start loading the car now, you don't need to wait for me to unlock it, it's already open.

Intuitively, the explication of the (relatively strong) implicatures gives the utterance quite a different flavour: it sounds as if Mike is impatient about Sally's slowness or unawareness of the situation. The reason is that in (18) implicatures have been made explicit which Sally could have been expected to infer on her own from the information that the car is open. This being manifest, the addressee is invited to look for further implications, since - by the definition of relevance - the explication of information which is already manifest to the addressee is not relevant unless further modifications of the addressee's knowledge are intended.

This means that the higher the degree of resemblance of the translation to the original is called for, the more important it is that contextual assumptions are not explicated in the translation, but that problems related to the contextual gap between primary and secondary audience be dealt with by adjusting the target audience's contextual competence. This can be achieved by various means. Turning to example (5), it seems that the addition of a translator's note explaining the relevant properties of Hebrew love songs will enable the audience to identify the intended interpretation. Apart from footnotes a whole range of options may exist including introductory articles to literary works or commentaries on the translation. See Gutt (1988) for further discussion. 
In the account of genre outlined in this paper the point was made that the mind is susceptible to adjust and add genre concepts, since such concepts can provide help for interpretation and thus reduce the audience's processing effort. This suggests that readers of a translation can acquire new genre information with relative ease. In this sense translations can be seen as effective bridges between cultures. Example (4) above is a case in point. The intuition that readers of translated novels can acquire knowledge of unfamiliar conventional elements can be explained in the following way: in the first place, the hearer can infer the intended interpretation even without recourse to genre information, though this requires some additional effort. On repeated encounters with conversational turns such as these, the first interpretation gets reinforced and the assumptions used to interpret them are stored in more accessible places in memory. Finally, arranging these assumptions under a single concept - a genre - may further improve their accessibility. It seems, then, that the enterprise of adjusting the target audience's contextual knowledge is especially promising with regard to genre information ${ }^{8}$, so that the strategy to overcome problems of genre by adjusting the target audience's context rather than the text is in general a realistic one.

There are thus two possible strategies to address genre problems in translation (as well as contextual gap problems more generally): to adjust the target audience's context and retain resemblance in genre properties, or to adjust the text and thus achieving a lower level of resemblance. Which strategy is adequate in a given situation depends crucially on what degree of resemblance the target audience regards as relevant, on the nature of the particular genre, on the function it has in the particular case, and on the preferences of the translator. In the following subsection I will discuss some of these factors in the examples of section (1).

\subsection{Choosing strategies for solving genre-based translation problems}

A text such as Isaiah 5:1-7 may be translated for an audience which is interested in reading and re-reading the text intensively (especially in its broader Biblical context) and expecting to eventually come to a closer understanding of it in line with the intention of the original author. In other words: an audience which expects a very high level of resemblance and which is motivated to put in quite some processing effort. For such an audience, a translation such as (5) would be appropriate. If this text should be translated for a different audience, one that expects to be able to understand the text without having to study it in depth, i.e. an audience that is not prepared to put in so much processing effort, then (16) or (17) would be more appropriate translations.

Consider now example (1). A translator may well choose a rendering such as (2) intending to resemble the meaning of the original as well as the way it was presented in the original (i.e. attempting a high level of resemblance). Such a rendering could be relevant for persons who are interested not only in the content but also in the way a certain resolution was presented. An example of such an audience could be leaders of the German branch of an international institution or company. But such leaders do normally have access to the English original themselves and don't need a translation. German employees further down 
the hierarchy may need to be informed - but for this audience, the content of international resolutions is normally all that is relevant to them, and it is doubtful that this audience would be willing to invest the effort needed to familiarize themselves with the original context. A translation such as (3) which adapts the text so as to resemble the main points of content but not the way in which it was expressed may serve their interests best. Likewise, even those people who would eventually want to refer to the English original but want to inform themselves quickly in German in their preparation for further meetings, e.g. German branch leaders, would be better served with such a translation. For all practical purposes, relevance considerations predict that such a partial-resemblance translation is most relevant in the case considered.

We have now seen two examples of partial-resemblance translations where problems of genre are dealt with by adapting the text: (16) (with its variant in (17)) and (3). Notice that these translations adapt the text in different ways: in (16) some information has been inserted in the text to make it possible to the target audience to appreciate the symbolic meaning of the text. In (3), the main information content of the original - the content of the motion and the reasons behind it - are presented in a way in which a German committee would express it. But these strategies are not interchangeable: in the case of (16) it just isn't possible to tell what a German author would do in the same situation. Likewise, in the case of (3) it is not obvious what expressions could be inserted so that the way the original was expressed can be adhered to without loss of relevance. The reason for this is that the respective genres are constituted in different ways, and this constrains what type of adjustment in the text could be made in the case of a partial-resemblance translation.

Let us now turn to the example of Homer's Odyssey, which Nida recommended to translate in prose in a translation into contemporary English. Here we have a different kind of genre again. Recall the above remarks in section 3 (page 13) that in this case genre information does not enter into comprehension: the knowledge that the Odyssey is a Greek epic does not contribute to the original audience's comprehension processes. This is a case where the classification of the text as belonging to a genre 'epic' or 'narrative' has no role to play in pragmatics. The difficulty caused by the epic poetry style are due to the fact that poetic devices are employed, and poetic devices increase the audience's processing effort while promising additional effects. Whether the author can succeed in communication with such a text depends first on the ability of the audience to access relevant contextual assumptions, and second on whether the audience trusts the promise of extra cognitive effects and is willing to invest the additional effort. A translator may well come to the conclusion that her contemporary English audience both lacks the contextual background and also the willingness to invest the effort for processing the poetic devices, wanting to read the translation mostly to inform themselves of the cast of the story. For such an audience, considerations of relevance will lead to the conclusion that it is best to translate the Odyssey in narrative prose. In this sense Gutt's relevance-theoretic account of translations can explain the intuition underlying Nida's recommendation, but it is also obvious that they are not conditioned by genre, since the kinds of genre involved (epic or poetry and narrative) are not ones which enter into the comprehension procedure here. 
Consider now a different readership: students of the history of literature, who may read the translation rather than the original as a short-cut in their studies. These readers would probably be interested in more than just the cast of the story and would also be quite interested in the poetic devices used. These readers are probably prepared to put in the effort to acquaint themselves with the original context and would expect a higher level of resemblance than that achieved in a translation in narrative style. Considerations of relevance will then lead to the conclusion to attempt a translation in poetic style. The relevance-theoretic account of translation thus sheds light on both intuitions: that a translation in narrative may be relevant for some audiences, but that it may fail to resemble the original closely enough for others.

So far, I have illustrated how the target audience's expectations of relevance and the properties and functions of the respective genre influence the choice of an appropriate translation. As noted above, the translator's preferences may be an important factor as well. Consider the translator of a Kurdish novel into German or English. She may well intend to let the target audience feel something of the different culture. After all, the very purpose of translating a novel from a rather different culture is probably to let the target audience get a glimpse into that culture, and the readers will probably read it for this very purpose. Hence the translator may adopt a preference to imitate typical ways of expression of the original language and culture in the translation, e.g. translate in the spirit of example (6).

\section{Conclusion}

In this paper I have discussed some translation problems which could be seen as being caused by the effects of genre. I then proposed a relevance-theoretic account of genre which treats genre information as information which is typically used to fine-tune expectations of relevance arising in discourse. This account predicts that genre can play different roles in comprehension: in some cases, when the genre raises strong and very specific expectations of how the discourse will proceed, the recognition of genre information may be essential. In other cases, the role of genre for comprehension may be weaker, and in still other cases the recognition of genre may not be necessary at all. This multi-facetted account of genre is made possible in relevance theory which comes with an explicit account of context selection and which, through its cognition-based account of communication, sheds light on the role of cultural knowledge. It was shown that this account of genre is powerful enough to identify the sources of translation problems attributed to genre effects, and, together with Gutt's explanatory account of translation, guide the translator in a principled way to adequate solutions in given situations. I would like to point out three conclusions in particular: first, not all the problems which are attributed to genre are in fact due to genre. Only in cases where genre information plays a role in comprehension is a translation problem due to genre mismatches. This highlights the necessity to distinguish genre as a notion which is supposed to play a role in comprehension, and genre as a notion which can be applied to post-pragmatic taxonomic interests. Only the former is of interest to 
pragmatics, and only this phenomenon can therefore cause problems in translation. Second, genre is not a communicative clue in the sense of Gutt $(1991 ; 2000 \mathrm{a}, \mathrm{b})$, hence translation problems involving genre mismatch are by nature instances of the contextual gap between primary and secondary audiences. These problems can realistically be addressed by an adjustment of the secondary audience's contextual knowledge, if the target audience's expectations of relevance call for a high degree of resemblance. Third, no general preferences for a certain strategy to overcome genre problems in translation can be established in the abstract, without reference to a particular translation task; rather, considerations of relevance as well as the nature of the particular genre interact in a causal way, and by careful consideration of these factors the translator is able to adopt an appropriate strategy in each case.

Finally, the relevance-theoretic account of genre proposed in this paper is based on an explicit account of the role of expectations of relevance in complex stimuli (such as texts). Such expectations can affect other properties of complex stimuli as well. Unger (2001) has shown that relevance expectations of this sort can shed interesting light on intuitions usually attributed to global coherence, including topicality and information grounding in discourse. Thus, the investigation of genre reviewed in this paper has the capacity to inspire further research in pragmatics in general.

\section{Notes}

1. I would like to thank Freddy Boswell, Ernst-August Gutt and Simone Müller for helpful comments on earlier drafts of this paper. Special thanks are due to Deirdre Wilson who stimulated my research on genre and relevance theory with invaluable comments and constant encouragement.

2. Used by permission of the Translation Department of SIL International.

3. Abbreviations: IDF indefinite; $2 S 2^{\text {nd }}$ person singular; PCL untranslatable particle; AUX auxiliary verb; $3 \mathrm{~S} 3^{\text {rd }}$ person singular; SJ subjunctive.

4. A detailed analysis of this text with respect to influences of genre on its interpretation can be found in Unger (2001, 149-167).

5. On the accessibility of contextual information with regard to memory organization and relevance see Sperber \& Wilson (1995: 145-151; 1996).

6. So far I have considered only examples of genres which lead to more or less specific expectations about cognitive effects. Are there also genres which relate more to the level of effects rather than to type of effects? Unger (2001) argues that the narrative poetry which appears to be widespread in the Middle East, in ancient and modern times, is a case in point. I don't consider this matter further here as it is not central to the concerns of this paper.

7. See e.g. Kotthoff (1995), who studies the genre of toasts in Georgian: freedom from the pattern and closeness to the same are both measures for artfulness in toast contests.

8. Though this may depend somewhat on the complexity of the genre in question, as ErnstAugust Gutt (personal communication) pointed out to me. 


\section{Works Cited}

Bender, J. and D. Wellbery (eds)(1990): The ends of rhetoric: History, theory, practice. Stantord, CA: Stanford University Press.

Birch, C. (1974): Studies in Chinese literary genres. Berkeley, CA: University of California Press. Blass, Regina (1990): Relevance relations in discourse. Cambridge: Cambridge University Press. Carruthers, Peter and Jill Boucher (eds)(1998): Language and thought. Cambridge: Cambridge University Press.

Carston, Robyn and Seiji Uchida (eds)(1998): Relevance theory: applications and implications. Amserdam and Philadelphia: John Benjamins.

Dijk, Teun A. van (ed)(1997): Discourse as structure and process. London: SAGE publications. Downing, Angela (1996): "Register and/or genre?". In I. Vázquez and A. Hornero, eds., Current issues in genre theory. Zaragoza: MIRA editores, 11-27.

Eggins, Suzanne and J. R. Martin (1997): "Genres and registers of discourse". In T. A. van Dijk, ed., Discourse as structure and process. London: SAGE publications, 230-256.

Fowler, Alasdair (1982): Kinds of literature: An introduction to the theory of genres and modes.

New York: Cambridge University Press.

Gerhart, Mary (1989): "The dilemma of the text: how to 'belong' to a genre". Poetics 18: 355-373. Gibbs, Raymond (1994): The poetics of mind. Cambridge: Cambridge University Press. Press. . (1999): Intentions in the experience of meaning. Cambridge: Cambridge University

Green, Mitchell S. (1995): "Quantity, volubility, and some varieties of discourse". Linguistics and Philosophy 18: 83-112.

Grice, H. P. (1957): "Meaning". The Philosophical Review 66: 377-388. Reprinted in H. P. Grice (1989).

(1967): William James Lectures. Reprinted in H. P. Grice (1989).

. (1989): Studies in the way of words. Cambridge MA: Harvard University Press.

Grimes, Joseph E. (1975): The Thread of Discourse. The Hague: Mouton.

Gutt, Ernst-August (1988): "From translation to effective communication". Notes on Translation 2(1): 24-40.

. (1991): Translation and relevance. Oxford: Blackwell.

(2000a): Translation and relevance. 2nd edition, Manchester: St. Jerome Publishing.

(2000b): "Textual properties, communicative clues and the translator". In P. Navarro

Errasti, R. Lorés Sanz, S. Murillo Ornat, and C. Buesa Gómez, eds., Transcultural communication: pragmalinguistic aspects. Zaragoza: ANUBAR, 151-160.

Holdcroft, David (1979): "Speech acts and conversation - I". The Philosophical Quarterly 29: 125-141.

Hönig, Hans G. and Paul Kußmaul (1982): Strategie der Übersetzung. Tübingen: Gunter Narr Verlag.

Kempson, Ruth (ed)(1988): Mental representations. Cambridge: Cambridge University Press,

Khalfa, Jean (ed)(1994): What is intelligence? Cambridge: Cambridge University Press.

Kitis, Eliza (1999): "On relevance again: From philosophy of language across "Pragmatics and power" to global relevance". Journal of Pragmatics 31: 643-667.

Klinge, Alex (1998): "Context construction and conventionalization". Paper presented at the Relevance Theory Workshop, University of Luton, 
Kotthoff, Helga (1995): "The social semiotics of Georgian toast performances: Oral genre as cultural activity". Journal of Pragmatics 24: 353-380.

Lakoff, George and Mark Johnson (1980): Metaphors we live by. Chicago: Chicago University Press.

Longacre, Robert E. (1983): The grammar of discourse. New York: Plenum Press.

Moser, H. (ed)(1974): Jahrbuch Gesprochene Sprache. Düsseldorf: Schwann.

Navarro Errasti, Pilar, Rosa Lorés Sanz, Silvia Murillo Ornat, Carmina Buesa Gómez (eds)(2000): Transcultural communication: pragmalinguistic aspects. Zaragoza: ANUBAR.

Nida, Eugene A. (1964): "Principles of correspondence". In E. A. Nida, Toward a science of translaing. Leiden: E. J. Brill, 156-171. Reprinted in L. Venuti, ed., The translation studies reader. London and New York: Routledge, 126-140.

Paltridge, Brian (1995): "Working with genre: a pragmatic perspective". Journal of Pragmatics 24: 393-406.

Pilkington, Adrian (1992): "Poetic effects". Lingua 87: 29-51.

(1994): Poetic thoughts and poetic effects. University of London, $\mathrm{PhD}$ thesis.

Reiss, Katharina (1981): "Type, kind and individuality of text: decision making in translation". Poetics Today 2(4): 121-131. Trans. Susan Kitron. Reprinted in Venuti (ed)(2000), 160-171.

Renkema, Jan (1993): Discourse Studies. An introductory textbook. Amsterdam/Philadelphia: John Benjamins Publishing Company.

Sperber, Dan (1994): "Understanding verbal understanding". In J. Khalfa, ed., What is intelligence? Cambridge: Cambridge University Press, 179-198.

. (1996): Explaining culture. Oxford: Blackwell.

(2000): "Metarepresentations in an evolutionary perspective". In D. Sperber, ed., Metarepresentations. Oxford: Oxford Universtiy Press, 117-137.

. (ed)(2000): Metarepresentations. Oxford: Oxford Universtiy Press.

Sperber, Dan and Deirdre Wilson (1990): "Rhetoric and relevance". In J. Bender and D. Wellbery, eds., The ends of rhetoric: History, theory, practice. Stanford, CA: Stanford University Press, 140-156.

. (1995): Relevance. Oxford: Blackwell (First edition, 1986).

(1996): "Fodor's frame problem and relevance theory". Behavioural and Brain Sciences, $19(3), 530-532$.

. (1998): "The mapping between the mental and the public lexicon". In P. Carruthers and J. Boucher, eds., Language and thought. Cambridge: Cambridge University Press, 184-200. Steger, H. et al. (1974): "Redekonstellationen, Redekonstellationstyp, Textexemplar, Textsorte im Rahmen eines Sprachverhaltensmodells. Begründung einer Forschungshypothese". In H. Moser, ed., Jahrbuch Gesprochene Sprache. Düsseldorf: Schwann, 39-97.

Swales, J. M. (1990): Genre analysis: English in academic and research settings. Cambridge: Cambridge University Press.

Thibault, Paul J. (1999): "Communicating and interpreting relevance through discourse negotiation: An alternative to relevance theory - A reply to Franken". Journal of Pragmatics 31: 557-594.

Unger, Christoph (2001): On the cognitive role of genre: a relevance-theoretic perspective. University of London, $\mathrm{PhD}$ thesis.

Vázquez Orta, Ignacio (1996): "Register, genre and linguistic choice". In I. Vázquez and A. Hornero, eds., Current issues in genre theory. Zaragoza: MIRA editores, 29-50. 
Vázquez, Ignacio and Ana Hornero (eds)(1996): Current issues in genre theory. Zaragoza: MIRA editores.

Venuti, Lawrence (ed)(2000): The translation studies reader. London and New York: Routledge.

Werlich, E. (1982): A Text Grammar of English. Heidelberg: Quelle and Meyer.

Wilson, Deirdre (2000): "Metarepresentation in linguistic communication". In D. Sperber, ed., Metarepresentations. Oxford: Oxford Universtiy Press, 411-448.

Wilson, Deirdre and Dan Sperber (1988): "Representation and relevance". In R. Kempson, ed, Mental representations. Cambridge: Cambridge University Press, 133-153.

. (1998): "Pragmatics and time". In R. Carston and S. Uchida, eds., Relevance.

theory: applications and implications. Amserdam and Philadelphia: John Benjamins, 1-22.

. (2000): "Truthfulness and relevance". UCL Working papers in linguistics 12:215-

257.

\section{Appendix}

Isaiah 5:1-7 Hebrew text with glosses

(la) ${ }^{\circ} \bar{a}-$ šîr-â nâ lî̀-dîd-î šîr-at dôd-î lə-ǩkarm-ô.

(la) I-will-sing HT to-friend-my song-of friend-my to-vineyard-his.

(1b) kerem hāyâ lî-dîd-î bə-qeren ben-šamen

(1b) vineyard there. was to-friend-my in-hilltop son-of=fat

(2a) wa-yə- ${ }^{c}$ azzeqēe-hû wa-yə-saqqalē-hû way-yitțăc ${ }^{c}$-hû sorēq

(2a) and-he-digged.up-it and-he-destoned-it and-he.planted-it red.ones

(2b) Way-yiben migdal bə-tôk k̂ô wə-gam=yeqeb hạașêv b-ô

(2b) and-he-built a-tower in-midst.of-it and-also=winevat he hew in-it

(2c) wa-yəqaw la- ăsôt cănābîm way-yacas bə ${ }^{p}$ ušîn.

(2c) and-he.waited for-to.bring good.grapes and-it.brought wild.grapes

(3) wə- ${ }^{c}$ attâ yôšēb yərûšãlayim wə- ${ }^{\text {î̉ }}$ yəhûdâ,

(3) and-now inhabitants.of Jerusalem and-man.of Judah,

šipṭ̂n=nâ bên-î $\hat{\mathrm{a}}$-b̆en karm-î.

judge $=\mathrm{HT}$ between-me and-between vineyard-mine.

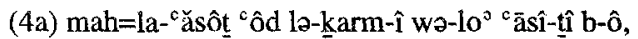

(4a) what=for-to.do more to-vineyard-mine and-not have.done-I for-it,

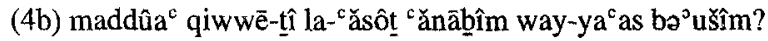

(4b) why have.waited-I to-bring good.grapes and-it.brought sour.grapes?

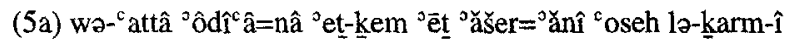

(5a) and-now I.let.know=HT ACC-you ACC what $=I$ do.PCP

to-vineyard-mine. 


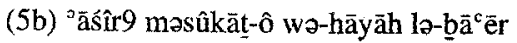

(5b) I.will.remove hedge-its and-it.will.become to-firewood

(5c) pāroș gədêer-ô wə-hāyāh la-mirmāśs

(5c) I.tear.down wall-its and-it.will.become to-trampled.land

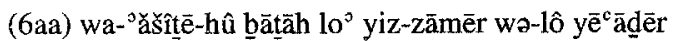

(6aa) and-bring-for.him peril not it-will.be.pruned and-not it-will be.hewn

(6ab) wə־`āā-āh šāmîr wã-šāyit

(6ab) and-on-it thorns and-thronbushes.

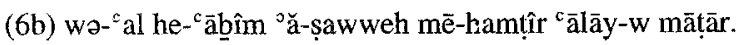

(6b) and-to the-clouds I-command from-raining on-it rain.

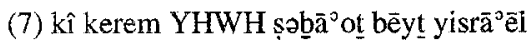

(7) For vineyard.of God of.hosts house Israel

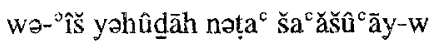

and-man.of Judah planting.of delight-his,

wa-ya-qaw lə-mišpāt wə-hinnēh mispāh̆,

and-he-waited for-justice and-behold injustice (or: bloodshed),

Ii-șdäqäh wə-hinnēh șəَâăäh .

for-righeousness and-behold cries. 